Rev. Bras. Saúde Prod. Anim., Salvador, v.13, n.1, p.181-191 jan/mar, 2012 http://www.rbspa.ufba.br ISSN 15199940

\title{
Inclusão de óleos essenciais como elementos fitoterapicos na dieta de suínos ${ }^{1}$
}

\author{
Inclusion of essential oils herbal dietary elements how swine
}

\author{
SILVA, Taisa Rocha Gomes da ${ }^{2 *}$; MARTINS, Terezinha Domiciano Dantas ${ }^{3}$; SILVA, \\ José Humberto Vilar ${ }^{3}$; SILVA, Ludmila da Paz Gomes da ${ }^{3}$; PASCOAL, Leonardo \\ Augusto Fonseca ${ }^{3}$; OLIVEIRA, Elton Roger Alves de ${ }^{2}$; BRITO, Mariany Sousa ${ }^{2}$
}

\author{
${ }^{1}$ Parte da dissertação do primeiro autor. \\ ${ }^{2}$ Universidade Federal da Paraíba, Centro de Ciências Agrárias, Departamento de Zootecnia, Areia, \\ Paraíba, Brasil. \\ ${ }^{3}$ Universidade Federal da Paraíba, Centro de Ciências Humanas Sociais e Agrárias, Departamento de \\ Agropecuária, Bananeiras, Paraíba, Brasil. \\ *E-mail para Correspondência: taisargsilva@gmail.com
}

\section{RESUMO}

Objetivou-se avaliar o desempenho de suínos na fase inicial e de crescimento alimentados com diferentes tipos de óleos essenciais de plantas adaptadas ao semiárido Nordestino. Foram utilizados 40 suínos da linhagem comercial Agroceres $^{\circledR}$, (20 machos castrados e 20 fêmeas) com peso vivo médio inicial de $13,5 \pm 3 \mathrm{~kg}$, distribuídos em um delineamento em blocos casualizados, com cinco tratamentos e quatro repetições. Os tratamentos consistiram na ração controle e outras quatro rações que continham $0,01 \%$ de óleos essenciais de ervadoce, marmeleiro, alfavaca e erva-cidreira. As variáveis avaliadas foram: desempenho, incidência de diarréia e perfil microbiológico. Não houve efeito da adição dos óleos essenciais para as variáveis de consumo de ração, ganho de peso, conversão alimentar e contagem de bactérias para os animais na fase inicial, apresentando influência da adição dos óleos para consumo de ração, conversão alimentar na fase de crescimento I e para consumo de ração na fase total. Os óleos essenciais de marmeleiro, erva-cidreira e alfavaca apresentaram um efeito positivo no controle da diarréia. Concluiu-se que os óleos essenciais de marmeleiro, ervacidreira e alfavaca, podem ser utilizados como antimicrobiano para combater a diarréia dos leitões, sem acarretar prejuízo no desempenho.

Palavras-chave: antimicrobiano, desempenho, incidencia de diarréia

\section{SUMMARY}

The objective was to evaluate the performance of starter pigs and growth fed with different types of essential oils from plants adapted to semiarid Northeast. A total of 40 pigs from commercial line Agroceres $\AA$, (20 castrated males and 20 females) with average weight of $13.5 \pm 3 \mathrm{~kg}$, distributed in a randomized block design with five treatments and four replicates, the treatments in the control diet and four diets containing diets $0.01 \%$ essential oils of fennel, quince, lemon grass and basil. The variables were: performance, incidence of diarrhea and microbiological perfil. No effect of addition of essential oils for the variables feed intake, weight gain, feed conversion and bacteria count for the animals in the initial stage, showing the influence of the addition of oil for feed intake, feed conversion during the growth phase I and phase feed intake in total. The essential oils of quince, lemon grass and basil had a positive effect on control of diarrhea. It was concluded that the essential oils of quince, lemon grass and basil, can be used as an antimicrobial agent to combat diarrhea of piglets without causing performance losses.

Keywords: antimicrobial, diarrhea incidence, performance 


\section{INTRODUÇ̃̃̃O}

A carne suína é atualmente uma das mais consumidas no mundo, é ótima fonte de proteína animal e, devido à produção de 100 milhões de toneladas/ano, o Brasil se encontra como o quarto maior produtor e exportador, com $3 \%$ da produção, e $11 \%$ das exportações (USDA; 2009).

No sistema de produção de suínos, a fase de desmame e de creche são as mais críticas para os animais. Por várias décadas, os antimicrobianos promotores de crescimento foram utilizados em dietas para suínos recém-desmamados e em crescimento, no intuito de diminuir a incidência de diarréia pós-desmame e promover melhora no desempenho animal (HERMANDÉZ et al., 2004). Na década de 90 o uso desses aditivos passou a ser visto como fator de risco para a saúde humana, principalmente em decorrência de duas contestações, a presença de resíduos dos antimicrobianos na carne, nos ovos e no leite e a indução de resistência cruzada para bactérias patogênicas para humanos (MENTEN, 2001).

Com isso, surgiram restrições quanto ao uso de antibióticos e quimioterápicos na alimentação animal. Este fato estimulou pesquisas de compostos que tivessem uma ação semelhante à dos antibióticos promotores de crescimento e que não interferissem negativamente no desempenho do animal (UTIYAMA et al., 2006).

Os óleos essenciais têm como principais constituintes o carvacrol e o timol, e agem contra os micro-organismos através de uma ação lipofílica na membrana celular, dispersando as cadeias de polipeptídeos que irão constituir a matriz da membrana celular (NOSTRO, 2004).

Os óleos essenciais diminuem o crescimento bacteriano e isso faz com que as bactérias produtoras de toxinas usem a energia para se manterem viáveis, assim há sobra de pouca ou nenhuma energia para a produção de toxinas. (ULTLEE et al., 1999).

Dentre as plantas com potencial para substituir os tradicionais promotores de crescimento no controle de problemas entéricos em suínos, pode-se destacar a Foeniculum vulgare (erva-doce), o Croton Sonderianus (marmeleiro), o Ocimum Gratissimum (alfavaca) e a Melissa officinalis (erva-cidreira) que possuem constituintes que podem atuar na melhoria do sistema imune do animal.

Este estudo foi realizado para avaliar o uso dos óleos essenciais de Foeniculum vulgare (Erva-cidreira), Croton Sonderianus (Marmeleiro), Ocimum Gratissimum (Alfavaca) e Melissa officinali (Marmeleiro), sobre o desempenho produtivo, a incidência de diarréia e a contagem de bactérias de suínos na fase inicial e de crescimento.

\section{MATERIAL E MÉTODOS}

Para avaliar a ação dos diferentes tipos de óleo essencial na dieta de suínos nas fases inicial (15 a $30 \mathrm{~kg}$ ), crescimento I (30 a $50 \mathrm{~kg})$ e crescimento II (50 a $70 \mathrm{~kg})$ foi conduzido um experimento no período de junho a setembro de 2009.

A extração dos óleos essencial foi feita por meio da técnica de hidrodestilação em aparelho de clevenger, em que o vapor, ao sair da caldeira e ao circular por onde a planta se encontra irá forçar a quebra das bolsas intercelulares, o que resulta na liberação dos óleos essenciais presentes na planta. Os óleos voláteis apresentam tensão de vapor mais elevada do que a da água, por isso são arrastados pelo vapor d'água passando pela serpentina que está em contato com 
água a uma temperatura mais baixa. A água e o óleo são condensados. Nesse produto de saída pode-se ver a diferença das duas fases, óleo na parte superior e, na inferior, a água. Elas são separadas pela decantação.

Para verificar a atividade dos óleos essenciais contra os principais patógenos que habitam o trato digestório dos leitões (Escherichia coli, Salmonella spp. e Staphylococcus spp.) foi realizado um ensaio de atividade antimicrobiana, em que os óleos essenciais foram testados "in vitro".

Utilizaram-se cepas de bactérias Staphylococcus aureus, Escherichia coli e Salmonella spp.. As cepas de Staphylococcus aureus foram mantidas em placas com meio Manitol Salgado e as cepas de Escherichia coli e Salmonella spp., em placas com meio MacConkey. Tubos de ensaio que continham $5 \mathrm{~mL}$ de água foram semeados com amostras cultivadas nas placas. $\mathrm{O}$ inóculo final foi diluído na concentração de 1:20 $\left(1,5 \times 10^{7}\right)$ em água destilada esterilizada.

Em seguida foi realizado um ensaio preliminar de triagem, para a verificação prévia dos óleos essenciais como possíveis agentes ativos por meio do método de disco-difusão em Ágar em placas de Petri ${ }^{\circledR}$ (90 X 10mm) com o meio de Müller-Hinton (DIFCO). Com ajuda de Swabs esterilizados, espalhou-se o inóculo por toda a superfície da placa. Posteriormente, discos de papel de filtro (CECON), estéreis padronizados, foram embebidos com $20 \mu \mathrm{L}$ de cada óleo essencial e fixados sobre a superfície do meio de Müller-Hinton.

Para a determinação da concentração inibitória mínima dos óleos essenciais foi utilizado o método de microdiluição. Foram utilizadas duas placas estéreis de 96 cavidades $\left(\right.$ CRALPLAST $\left.^{\circledR}\right)$, as quais, em duplicatas foram distribuídas em cada cavidade $100 \mu \mathrm{L}$ de água destilada esterilizada. $\mathrm{Na}$ cavidade da linha A da placa adicionou-se $100 \mu \mathrm{L}$ de uma emulsão de óleo essencial. Em seguida, procederam-se as diluições seriadas transferindo-se $100 \mu \mathrm{L}$ da linha A até a linha $G$ da placa. A linha $H$ foi deixada sem óleo e serviu como controle positivo. Posteriormente, em cada cavidade adicionou-se $10 \mu \mathrm{L}$ do inóculo das espécies de Staphylococcus aureus, Escherichia coli e Salmonella spp. As placas foram seladas e incubadas por 24 horas a temperatura de $37^{\circ} \mathrm{C}$ e atmosfera normal. Decorrido o tempo de incubação, adicionou-se $20 \mu \mathrm{L}$ da solução aquosa $(0,01 \%)$ de Resazurin $\left(\operatorname{SIGMA}^{\circledR}\right)$ em cada cavidade, e as placas foram reincubadas por mais 12 horas, quando se procedeu a leitura (BANFI et al., 2003).

Para a verificação de aceitabilidade dos animais foi feito um teste de consumo mediante utilização de 12 animais da linhagem comercial Agroceres ${ }^{\circledR}$, sendo distribuídos dois machos por baia. O teste teve duração de quatro dias e em cada dia, os leitões recebiam rações que continham $0,01 \%$ dos óleos essenciais estabelecidos no ensaio "in vitro" de concentração mínima inibitória, para determinação do nível de inclusão de cada óleo testado, tendo um tratamento com óleo essencial de ervadoce (Ed), marmeleiro (Ma), alfavaca (Av), erva-cidreira, (Ec), e óleo essencial de um preparado de todas as plantas na proporção de $25 \%$ de inclusão de cada um (Mist).

Foi conduzido um experimento de desempenho, no qual foram utilizados 40 leitões (20 machos castrados e 20 fềmeas) da linhagem comercial Agroceres ${ }^{\circledR}$, com peso médio inicial de $13,5 \pm 3,5 \mathrm{~kg}$ (42 dias de vida). Os animais foram distribuídos em um delineamento em blocos casualizados, com cinco tratamentos, quatro repetições e dois animais por unidade experimental (um macho castrado e uma fêmea). 
Os animais foram alojados em baias de piso $1 / 3$ ripado com área de $3,91 \mathrm{~m}^{2}$ cada, equipadas com comedouros de alvenaria e bebedouros do tipo chupeta. As temperaturas médias mínimas $\mathrm{e}$ máximas registradas foram $23,1^{\circ} \mathrm{C}$ e $26,0^{\circ} \mathrm{C}$, respectivamente, por meio de mensurações realizadas diariamente.

Os tratamentos foram: controle $(\mathrm{C})=$ dieta basal, composta principalmente por milho e farelo de soja sem adição de nenhum promotor de crescimento; e quatro dietas com a inclusão de 0,01\% de óleo essencial de erva-doce (Ed), marmeleiro (Ma), alfavaca (Av) ou erva-cidreira (Ec). As dietas foram formuladas para atender as exigências nutricionais de animais de alto potencial genético na fase inicial $e$ de crescimento, de acordo com as recomendações de Rostagno et al. (2005) - (Tabela 1).

Tabela 1. Composição percentual e calculada das dietas basais para suínos na fase inicial (15 a 30kg), crescimento I (30 a $50 \mathrm{~kg})$ e crescimento II (50 a $70 \mathrm{~kg})$

\begin{tabular}{|c|c|c|c|}
\hline \multirow[b]{2}{*}{ Ingredientes (\%) } & \multicolumn{3}{|c|}{ Fases } \\
\hline & $\begin{array}{c}\text { Inicial } \\
(15 \text { a } 30 \mathrm{~kg})\end{array}$ & $\begin{array}{l}\text { Crescimento I } \\
(30 \text { a } 50 \mathrm{~kg})\end{array}$ & $\begin{array}{l}\text { Crescimento II } \\
(50 \text { a } 70 \mathrm{~kg})\end{array}$ \\
\hline Milho & 67,41 & 70,57 & 73,67 \\
\hline Farelo de Soja & 28,41 & 25,82 & 22,70 \\
\hline Fosfato bicálcico & 1,58 & 1,22 & 0,97 \\
\hline Calcário & 0,56 & 0,58 & 0,56 \\
\hline Óleo de soja & 0,30 & 0,60 & 0,56 \\
\hline L-lisina HCL $(78,4 \%)$ & 0,40 & 0,32 & 0,32 \\
\hline DL-metionina & 0,10 & 0,08 & 0,06 \\
\hline L-treonina & 0,13 & 0,10 & 0,09 \\
\hline Premix vitamínico ${ }^{1}$ & 0,10 & 0,10 & 0,10 \\
\hline Premix mineral $^{2}$ & 0,10 & 0,10 & 0,10 \\
\hline Sal comum & 0,40 & 0,40 & 0,36 \\
\hline $\mathrm{BHT}^{3}$ & 0,01 & 0,01 & 0,01 \\
\hline Inerte $^{4}$ & 0,50 & 0,10 & 0,50 \\
\hline Óleo essencial $^{5}$ & - & - & - \\
\hline Total & 100,00 & 100,00 & 100,00 \\
\hline \multicolumn{4}{|l|}{ Valores calculados $^{6}$} \\
\hline Energia metabolizável (kcal/kg) & 3.184 & 3.230 & 3.230 \\
\hline Proteína bruta (\%) & 19,25 & 18,25 & 17,00 \\
\hline Fibra bruta $(\%)$ & 1,82 & 2,90 & 2,78 \\
\hline Lisina Digestível (\%) & 1,14 & 1,02 & 0,95 \\
\hline Metionina + cistina Digestível (\%) & 0,64 & 0,61 & 0,57 \\
\hline Metionina Digestível (\%) & 0,36 & 0,35 & 0,31 \\
\hline L-treonina Digestível(\%) & 0,72 & 0,66 & 0,61 \\
\hline Cálcio (\%) & 0,72 & 0,63 & 0,56 \\
\hline Fósforo disponível (\%) & 0,40 & 0,33 & 0,28 \\
\hline Sódio (\%) & 0,20 & 0,18 & 0,17 \\
\hline \multicolumn{4}{|c|}{$\begin{array}{l}\text { Quantidade por kg de alimento: Vitamina A } 200.000 \text { U.I, Vitamina } \mathrm{D}_{3} 800.000 \text { U.I; vitamina E } 800 \text { U.I, } \\
\text { Vitamina } \mathrm{K}_{3} 40 \mathrm{mg} \text {, Vitamina } \mathrm{B}_{1} 40 \mathrm{mg} \text {, Vitamina } \mathrm{B}_{2} 80 \mathrm{mg} \text {, Vitamina } \mathrm{B}_{6} 30 \mathrm{mg} \text {, Vitamina } \mathrm{B}_{12} 400 \mathrm{mg} \text {, } \\
\text { Niacina } 300 \mathrm{mg} \text {, Acido pantotênico } 200 \mathrm{mg} \text {, Biotina } 1 \mathrm{mg} \text {, Ácido fólico } 5 \mathrm{mg} \text {, Selênio } 5 \mathrm{mg} \text {, Colina } 5 \mathrm{mg} \text {, } \\
\text { Antioxidante } 2.000 \mathrm{mg} \text {, Veiculo Q.S.P. } 20 \mathrm{gr} ;{ }^{2} \text { Quantidade por kg de alimento: Manganês } 1.400 \mathrm{mg} \text {, Zinco } \\
2.000 \mathrm{mg} \text {, Ferro } 800 \mathrm{mg} \text {, Cobre } 200 \mathrm{mg} \text {, Cobalto } 4 \mathrm{mg} \text {, Iodo } 30 \mathrm{mg} \text {, Antioxidante } 2.000 \text {, Veículo q.s.p. } \\
\text { 20gr; }{ }^{3} \mathrm{BHT}=\text { Butil Hidroxi Tolueno; }{ }^{4} \text { Inerte }=\text { Areia lavada; }{ }^{5} \text { Óleo essencial de erva-doce, marmeleiro, } \\
\text { alfavaca ou erva-cidreira }(0,01 \%) ;{ }^{6} \text { Composição calculada segundo Rostagno et al. (2005). }\end{array}$} \\
\hline
\end{tabular}


Os animais receberam ração e água à vontade. Os óleos essenciais foram fornecidos com base no consumo diário dos animais, diluídos no óleo de soja e misturados na ração. As doses dos óleos essenciais + óleo de soja, foram misturadas na proporção de $25 \%$ do consumo diário de ração total dos suínos, fornecida pela manhã. Após a observação do consumo da ração com o óleo, as rações eram ofertadas à vontade. As rações desperdiçadas eram recolhidas, pesadas e descontadas do consumo diário e o peso individual dos animais registrados no inicio e final da fase inicial (15 a $30 \mathrm{~kg}$ ) e crescimento (30 a 70kg). Com base nesses dados foram determinados o consumo diário de ração (CDR, g/dia), o ganho diário de peso (GDP, g/dia) e a conversão alimentar $(\mathrm{CA}, \mathrm{g} / \mathrm{g})$ dos animais.

Para a análise de incidência de diarréia, os animais da fase inicial foram observados diariamente, pelo mesmo observador, às $08 \mathrm{~h}$ e às $16 \mathrm{~h}$ por 30 minutos, durante 29 dias, sendo um total de 58 observações, no intuito de avaliar visualmente a consistência das fezes, as quais foram classificadas de 0 a 3: em que 0 - fezes normais, 1 - fezes pastosas, 2 - fezes pastosas/líquidas e 3 - fezes líquidas. Os escores dois ou três eram considerados como indicativo de diarréia (CASTILLO et al., 2008). As observações eram tabuladas com o somatório das vezes em que foi observado o escore dois e três, sobre o total de observações registradas para os 40 animais.

O perfil microbiológico fecal (bactérias Gram + -) foi determinado em um animal de cada repetição, o que totalizou 20 animais na fase inicial, aos 56 e 71 dias de idade. Para a coleta das amostras foram utilizados swabs estéries preparados em tubos com $10 \mathrm{ml}$ de água peptonada $0,1\left(\mathrm{H}_{2} \mathrm{O}_{\mathrm{p}}\right)$. O swab foi colocado no reto do animal de modo que toda a superfície do algodão entrasse em contato com a amostra. Após a coleta da amostra, o swab foi transferido para o tubo de ensaio e enviado ao laboratório, onde foram preparados tubos de ensaios com oito diluições, sendo transferido $1 \mathrm{ml}$ da diluição anterior para $9 \mathrm{ml}$ de diluente, prosseguindo desta forma até chegar às diluições cinco, seis, sete e oito. As amostras foram colocadas em placas e identificadas, e em seguida foram utilizados os meios de culturas Mackonkey (MAC) $0,15 \%$ e caldo lactose eosina dextrose (CLED) que são especificos para o crescimento de micro-organismos gram positivo e gram negativo, levadas para a estufa a $35^{\circ} \mathrm{C}$ por um período de 48 horas e, posteriormente, realizada as leituras das bactérias por contagem de colônias existentes.

Os dados de desempenho foram submetidos à análise de variância e posteriormente ao teste SNK ao nível de $5 \%$ de probabilidade, mediante a utilização do procedimento "General Linear Model" (GLM) do software estatístico "Statistical Analysis System" (SAS INSTITUTE, 1997).

Para a análise estatística dos dados de incidência de diarréia foi utilizado o teste não paramétrico de Kruskall Wallis a 5\% de significância, e para a análise de contagem de bactérias os dados foram transformados pela função $y=\log x$, em que $x$ é o número de unidades formadoras de colônias por grama de amostra (ufc/g) e submetidos ao teste SNK ao nível de $5 \%$ de probabilidade pelo "General Linear Model" (GLM) do software estatístico "Statistical Analysis System" (SAS INSTITUTE, 1997). 
Rev. Bras. Saúde Prod. Anim., Salvador, v.13, n.1, p.181-191 jan/mar, 2012 http://www.rbspa.ufba.br ISSN 15199940

\section{RESULTADOS E DISCUSSÃO}

Os rendimentos dos óleos essenciais extraídos foram $1 \%$ para erva-doce, $0,26 \%$ para marmeleiro, $0,22 \%$ para alfavaca e $0,24 \%$ para erva-cidreira. Com relação ao grau de ativação dos óleos essenciais, o maior elo de inibição das bactérias Staphylococcus aureus, Escherichia coli e Salmonella spp. foi obtido com o óleo de marmeleiro, seguido de erva-cidreira e alfavaca. $\mathrm{O}$ óleo de erva-doce não se mostrou ativo diante das espécies de bactérias analisadas (Tabela 2).

Tabela 2. Concentração inibitória mínima dos óleos essenciais de erva-doce, marmeleiro, alfavaca, e erva-cidreira diante das espécies de Staphylococcus aureus, Escherichia coli e Salmonella spp

\begin{tabular}{lc}
\hline Óleos essenciais & (Concentração Inibitória Mínima) \\
\hline Erva-doce (Foeniculum vulgare ) & Não Determinado \\
Marmeleiro (Croton Sonderianus) & $1 \mathrm{mg} \backslash \mathrm{ml}$ \\
Alfavaca (Ocimum gratíssimum) & $750 \mu \mathrm{g} \backslash \mathrm{ml}$ \\
Erva-cidreira (Melissa Oficinalis) & $200 \mathrm{mg} \backslash \mathrm{ml}$ \\
\hline
\end{tabular}

Conteúdo obtido após análise da Concentração Inibitória Mínima.

Os animais aceitaram bem a quantidade de óleo essencial fornecido nas rações, demonstrando que a sua inclusão não influenciou o consumo dos animais por um período de quatro dias de avaliação (Tabela 3).

Tabela 3. Consumo de ração diário em função dos diferentes óleos essenciais durante o ensaio de aceitabilidade

\begin{tabular}{lc}
\hline Tratamentos & $\begin{array}{c}\text { Consumo de ração } \\
\text { diário }(\mathrm{g} / \mathrm{dia})^{1}\end{array}$ \\
\hline Controle & $1.284,87$ \\
Erva-doce & $1.269,25$ \\
Marmeleiro & $1.228,25$ \\
Alfavaca & $1.318,75$ \\
Erva-cidreira & $1.304,62$ \\
Mistura (25\%) & $1.215,25$ \\
\hline
\end{tabular}

${ }^{1}$ Valores médios, não analisados estatisticamente.
Os óleos essenciais não influenciaram $(\mathrm{P}>0,05)$ o consumo de ração diário, o ganho de peso diário e conversão alimentar na fase inicial. $\mathrm{Na}$ fase de crescimento, as adições dos óleos essenciais reduziram $(\mathrm{P}<0,05)$ o consumo de ração diário e a conversão alimentar (Tabela 4).

É sabido que a adição em excesso dos óleos essências de plantas no consumo dos animais pode causar intoxicação e assim diminuir a palatabilidade da ração, uma vez que os suínos são animais extremamente sensíveis no paladar, fato este que pode ter acontecido para a redução do consumo de ração pelos animais na fase de crescimento.

No período dos 15 aos $70 \mathrm{~kg}$ (fase total) o consumo de ração diário foi menor $(\mathrm{P}<0,05)$ quando os animais receberam óleo de marmeleiro na dieta sem que houvesse diferença entre os demais resultados. Não houve efeito $(\mathrm{P}>0,05)$ dos óleos essenciais sobre a conversão alimentar. 
Rev. Bras. Saúde Prod. Anim., Salvador, v.13, n.1, p.181-191 jan/mar, 2012 http://www.rbspa.ufba.br ISSN 15199940

Tabela 4. Médias de consumo diário de ração (CDR), ganho diário de peso (GDP), e conversão alimentar (CA) de suínos na fase inicial (15 a 30kg), crescimento (15 a 50kg) e total (15 a 70kg) em função dos diferentes óleos essenciais

\begin{tabular}{|c|c|c|c|c|c|c|}
\hline \multicolumn{7}{|c|}{ Tratamentos } \\
\hline \multirow{2}{*}{ Item } & $\mathrm{C}$ & $\mathrm{Ed}$ & $\mathrm{Ma}$ & Av & Ec & \multirow{2}{*}{$\begin{array}{l}C^{1} \\
(\%)\end{array}$} \\
\hline & \multicolumn{5}{|c|}{ Inicial } & \\
\hline CDR (g/dia) & 1131,40 & 1212,51 & 1100,00 & 1337,52 & 1125,00 & 14,18 \\
\hline GDP (g/dia) & 531,41 & 691,40 & 634,20 & 703,72 & 697,11 & 22,55 \\
\hline $\mathrm{CA}(\mathrm{g} / \mathrm{g})$ & 2,14 & 1,79 & 1,71 & 2,02 & 1,61 & 21,82 \\
\hline \multicolumn{7}{|c|}{ Crescimento } \\
\hline CDR (g/dia) & $1.944,00^{\mathrm{a}}$ & $1.707,50^{b}$ & $1.662,50^{\mathrm{b}}$ & $1.800,13^{\mathrm{ab}}$ & $1.680,00^{b}$ & 9,82 \\
\hline GDP (g/dia) & 699,63 & 715,00 & 692,50 & 755,38 & 750,00 & 15,73 \\
\hline $\mathrm{CA}(\mathrm{g} / \mathrm{g})$ & $2,96^{\mathrm{a}}$ & $2,42^{\mathrm{ab}}$ & $2,45^{\mathrm{ab}}$ & $2,41^{\mathrm{ab}}$ & $2,15^{\mathrm{b}}$ & 22,19 \\
\hline \multicolumn{7}{|c|}{ Total } \\
\hline CDR (g/dia) & $1.803,13^{\mathrm{ab}}$ & $1.817,50^{\mathrm{ab}}$ & $1.727,50^{b}$ & $1.924,63^{\mathrm{a}}$ & $1.780,00^{\mathrm{ab}}$ & 6,60 \\
\hline GDP (g/dia) & 819,25 & 807,75 & 810,63 & 846,50 & 810,88 & 10,50 \\
\hline $\mathrm{CA}(\mathrm{g} / \mathrm{g})$ & 2,22 & 2,25 & 2,15 & 2,30 & 2,20 & 9,28 \\
\hline
\end{tabular}

$\mathrm{C}=$ controle negativo; $\mathrm{Ed}=$ erva-doce; $\mathrm{Ma}=$ marmeleiro; $\mathrm{Av}=$ alfavaca; $\mathrm{Ec}=$ erva-cidreira; médias seguidas da mesma letra na linha não diferem pelo teste SNK $(\mathrm{p}>0,05)$.

${ }^{1}$ Coeficientes de variação.

Um dos modos de ação atribuído aos óleos essenciais pode ser o efeito antimicrobiano. Em um estudo in vitro realizado por Dorman \& Deans (2000), os óleo essencial de cravo, tomilho e orégano apresentaram pronunciado efeito antimicrobiano sobre determinados patógenos. $\mathrm{O}$ efeito antimicrobiano está relacionado, principalmente, com a alteração da permeabilidade e integridade da membrana celular bacteriana (LAMBERT et al., 2001).

O modo de ação dos óleos essenciais em experimento in vivo não foi totalmente esclarecido e comprovado. Alguns trabalhos relatam respostas positivas do uso de óleo essencial na dieta e outros não. Frangos alimentados com uma combinação de óleo essencial apresentaram maior ganho de peso (625 vs 578g/dia) e melhor conversão alimentar $(1,44$ vs 1,56) do que os animais do tratamento controle (JAMROZ \& KAMEL, 2002). De acordo com os autores, a suplementação com óleos essenciais aumentou a digestibilidade dos nutrientes e favoreceu a microbiota, o que diminuiu a adesão de patógenos ao epitélio intestinal.

Segundo Knowles (2005), a ação antimicrobiana dos óleos essenciais sobre a microbiota intestinal pode controlar ou inibir o crescimento dos patógenos e, consequentemente, proporcionar crescimento dos microorganismos benéficos, o que favorece $o$ desempenho animal.

Essas substâncias agem sobre as bactérias e/ou fungos sensíveis ao promover a morte do agente (efeito bactericida) ou ao interromper seu crescimento e sua reprodução (efeito bacteriostático). Esses efeitos podem ocorrer na síntese da parede celular dos micro-organismos, $\mathrm{o}$ que altera a permeabilidade da membrana citoplasmática e interfere na replicação cromossômica e na síntese proteica celular (MELLOR, 2000). Podem também promover economia de nutrientes, controlar doenças subclínicas 
e atuar sobre o metabolismo animal (MENTEM, 2001) o que acarreta melhor eficiência na utilização do alimento e, consequentemente, melhor desempenho.

Em experimentos com leitões, a inclusão de $0,75 \%$ de uma combinação de óleo essencial não influenciou o desempenho na fase inicial (SANTIN, 2001). Para suínos na fase de crescimento, o efeito benéfico da utilização de óleo essencial na dieta está relacionado com a melhora na conversão alimentar. Essa hipótese é confirmada por Thaler et al., (2004), que obtiveram respostas positivas sobre a eficiência alimentar de suínos na fase de crescimento, quando suplementados com uma combinação de OE.

Com a inclusão dos óleos essenciais, houve uma menor $(\mathrm{P}<0,01)$ incidência de diarréia nos animais experimentais em relação ao tratamento controle (Tabela 5), com exceção do óleo essencial de erva-doce que se mostrou menos eficiente no controle da diarréia.

Tabela 5. Incidência de diarréia medida em escore fecal, em função dos diferentes óleos essenciais

\begin{tabular}{|c|c|c|c|c|c|c|c|}
\hline \multirow{2}{*}{ Escore } & \multicolumn{5}{|c|}{ Tratamentos } & \multirow{2}{*}{ Total } & \multirow{2}{*}{$\%$, Escore } \\
\hline & $\mathrm{C}$ & Ed & $\mathrm{Ma}$ & Av & Ec & & \\
\hline 0 & 17 & 13 & 52 & 26 & 25 & 133 & 22,73 \\
\hline 1 & 79 & 72 & 62 & 72 & 81 & 366 & 62,57 \\
\hline 2 & 21 & 32 & 3 & 19 & 11 & 86 & 14,70 \\
\hline 3 & 0 & 0 & 0 & 0 & 0 & 0 & 0,00 \\
\hline Total & 117 & 117 & 117 & 117 & 117 & 585 & 100 \\
\hline $2(\%)$ & $17,94^{\mathrm{b}}$ & $27,35^{\mathrm{a}}$ & $2,56^{\mathrm{e}}$ & $16,24^{\mathrm{c}}$ & $9,40^{\mathrm{d}}$ & - & - \\
\hline
\end{tabular}

$\mathrm{C}=$ controle negativo; $\mathrm{Ed}=$ erva-doce $\mathrm{Ma}=$ marmeleiro; $\mathrm{Av}=$ alfavaca $; \mathrm{Ec}=$ erva-cidreira.

*Escore 2 e 3 são considerados diarréia.

Teste não paramétrico de Kruskall Wallis $(\mathrm{P}<0,01)$.

O menor índice de diarréia foi obtido com o tratamento que recebeu óleo essencial de marmeleiro $(\mathrm{P}<0,01)$, o que indica uma possível utilização como antimicrobiano para manutenção da saúde do trato gastrointestinal de suínos na fase inicial.

A diarréia em leitões pode ser causada principalmente pela colonização da superfície epitelial por patógenos, tais como Escherichia Coli enterotoxigenica, salmonella e Clostidium spp., e pela presença de resíduos alimentares não digeridos e não absorvidos, que servem como substratos para os microorganismos patogênicos. Os resíduos de alimentos, juntamente com ions minerais (sódio, potássio e cloro) presentes no epitélio intestinal, contribuem para o aumento da osmolaridade do conteúdo intestinal, o que dificulta o processo de reabsorção de água e assim desencadear a diarréia (BOTSOGLOU et al., 2002). Existe uma relação entre a estrutura química dos compostos ativos presentes nos óleo essencial e seu efeito antimicrobiano (BOTSOGLOU et al., 2004) e, geralmente, esse efeito pode ser atribuído à presença de compostos fenólicos (DORMAN \& DEANS, 2000). Alguns óleos essenciais apresentam alto poder antimicrobiano sobre diversos patógenos em estudos in vitro. Esta também pode ser uma das 
Rev. Bras. Saúde Prod. Anim., Salvador, v.13, n.1, p.181-191 jan/mar, 2012 http://www.rbspa.ufba.br ISSN 15199940

explicações para que o tratamento com extratos vegetais tenha apresentado melhor efeito sobre a frequência de diarréia, com exceção do tratamento com erva-doce, que foi o menos eficiente.

Não houve diferença $(\mathrm{P}>0,05)$ entre os tratamentos para a contagem de bactérias gram $(+)$ e gram (-), o que pode ser um indicativo de que o óleo essencial atua na modificação da microbiota e não na redução do número de micro-organismos associados com a idade dos animais ou nível testado (Tabela 6).

Tabela 6. Contagens de micro-organismos fecais (log UFC/g) dos suínos na fase inicial em função dos diferentes tratamentos: controle $(C)$, erva-doce $(\mathrm{Ed})$, marmeleiro (Ma), alfavaca (Av) e erva-cidreira (Ec)

\begin{tabular}{lcccccc}
\hline \multicolumn{7}{c}{ Tratamentos } \\
\hline Idade & $\mathrm{C}$ & $\mathrm{Ed}$ & $\mathrm{Ma}$ & $\mathrm{Av}$ & $\mathrm{Ec}$ & $\mathrm{CV}^{1}(\%)$ \\
\hline 56 dias & & & & & & \\
\hline Gram (-) & 0,423 & 0,816 & 0,827 & 0,664 & 0,441 & 34,83 \\
Gram (+) & 0,729 & 0,787 & 0,774 & 0,745 & 0,655 & 17,69 \\
\hline 71 dias & & & & & & \\
\hline Gram $(-)$ & 0,891 & 0,887 & 0,964 & 0,735 & 0,935 & 15,43 \\
Gram $(+)$ & 1,007 & 0,981 & 0,810 & 1,009 & 1,014 & 16,90 \\
\hline
\end{tabular}

${ }^{\top}$ Coeficientes de variação.

Alterações na microbiota foram confirmadas por Pedroso et al. (2005) ao relatarem que animais que receberam antimicrobianos apresentaram perfil diferenciado de bactérias em relação aos do tratamento controle. Entretanto, sabe-se que a composição bacteriana nas fezes pode apresentar grandes variações (PEDROSO et al. 2005) e isso pode ter influenciado os resultados encontrados.

O óleo essencial de erva-cidreira é indicado para leitões na fase de crescimento, pois melhorara o consumo diário de ração e a conversão alimentar. Já o óleo essencial de marmeleiro é indicado para leitões na fase inicial e pode atuar como antimicrobiano, uma vez que houve diminuição da incidência de diarréia.

\section{REFERÊNCIAS}

BANFI, E.; SCIALINO, G.; MONTIBRAGADIN. Development of a microdilution method to evaluate Mycobacterium tuberculosis drug susceptibility. Journal of Antimicrobial Chemotherapy, v.52, n. 2 p.796-800, 2003.

\section{BOTSOGLOU, N.A; FLOROU-}

PANERI, P.; CHRISTAKI, E. Effect of dietary oregano essential oil on performance of chickens and on ironinduced lipid oxidation of breast, thigh and abdominal fat tissues. British

Poultry Science, v.43, n.2, p.223-230, 2002. 
Rev. Bras. Saúde Prod. Anim., Salvador, v.13, n.1, p.181-191 jan/mar, 2012 http://www.rbspa.ufba.br ISSN 15199940

BOTSOGLOU, N.A.; FLOROUPANERI, P.; CHRISTAKI, E.; GIANNENAS, I.; SPAIS, A.B. Performance of rabbits and oxidative stability of muscle tissues as affected by dietary supplementation with oregano essential oil. Archives of Animal Nutrition, v.58, n.3, p.209218,2004

CASTILLO, M; MARTÍN-ORÚE, S.M.; TAYLOR-PICKARD, J.A. Use of mannan-oligosaccharides and zinc chelate as growth promoters and diarrhea preventative in weaning pigs: Effects on microbiota and gut function. Journal of Animal Science, v.86, n. 2, p.94-101, 2008.

DORMAN, H.J.D; DEANS, S.G. Antimicrobial agents from plants: antibacterial activity of plant volatile oils. Journal of Applied

Microbiology, v.88, n.3, p.308-316, 2000 .

HERNÁNDEZ, F; MADRID, J.; GARCIA,V. Influence of two plant extracts on broilers performance, digestibility, and digestive organ size. Poultry Science, v.83, n.3, p.169174, 2004.

JAMROZ, D.; KAMEL, C. Plant extracts enhance broiler performance. Journal of Animal Science, v.80, p.41, 2002. Suppl. 1.

KNOWLES, J.R. Antimicrobial action of carvacrolat different stages of dual-species biofilm development by Staphilococcus aureus and Salmonella enterica serovar Typhymurium. Applied and Environmental Microbiology, v.71, n.2, p.797-803, 2005.
LAMBERT, R.J.W; SKANDAMIS, P.N.; COOTE, P.J. A study of the minimum inhibitory concentration and mode of action of oregano essential oil, thymol and carvacrol. Journal of Applied Microbiology, v.91, p.453-462, 2001.

MELLOR, S. Herbs and spices promote health and growth. Pig Progress, v.16, n. 4, p. 18-21, 2000.

MENTEN,J.F.M. Eficácia, efeito sinérgico e modo de ação de agentes antimicrobianos como promotores do crescimento de suínos. 2001. 106p. Tese (Livre Docência em Nutrição de Suínos) - Escola Superior de Agricultura "Luiz de Queiroz", Universidade de São Paulo, Piracicaba..

NOSTRO, A. Susceptibility of methicilin-resistant Staphylococci to oregano essential oil, carvacrol, and thymol. FEMS Microbiology Letters, v.230, n.3, p.191-195, 2004.

PEDROSO, A.A; OETTING, L.L.; UTIYAMA, C.E.Variabilidade espacial da comunidade bacteriana intestinal de suínos suplementados com antibióticos ou extratos herbais. Revista Brasileira de Zootecnia, v.34, n.4, p.1225-1233, 2005.

ROSTAGNO, H.S; ALBINO, L.F.T.; DONZELE, J.L. Tabelas brasileiras para aves e suínos: composição de alimentos e exigências nutricionais. 2.ed. Viçosa: Universidade Federal de Viçosa, 2005. 186p.

SANTIN, E. Performance and intestinal mucosa development of broiler chickens fed diets containing Sacharomyces cerevisae cell wall. The Journal of Applied Poultry Research, v.10, n.2, p.236-244, 2001. 
Rev. Bras. Saúde Prod. Anim., Salvador, v.13, n.1, p.181-191 jan/mar, 2012 http://www.rbspa.ufba.br ISSN 15199940

SAS INSTITUTE. Statistical analysis system: user's guide: statistic. Cary, 1997.

THALER, R.C.; ROPS, B.D.;

CHRISTOPHERSON, B.T. Efficacy of SUPROL as a growth promotant for grow-finish pigs. Journal of Animal Science, v.82, p.99, 2004. Suppl.1.

UNITED STATES DEPARTMENT OF AGRICULTURE - USDA. Foreign agricultural service. Disponível em: $<$ http://www.fas.usda.gov $>$. Acesso em: 14 out. 2009.
ULTEE, A.; KETS, E.P.W.; SMID, E.J. Mechanisms of action of carvacrol on the foodborne pathogen Bacillus cereus. Applied and Environmental Microbiology, v.65, n.1, p.4606-4610, 1999.

UTIYAMA, C.E; OETTING, L.L.; GIANI, P.A. Efeitos de antimicrobianos, prebióticos e extratos vegetais sobre a microbiota intestinal, freqüência de diarréia e o desempenho de leitões racém- desmamados. Revista Brasileira de Zootecnia, v.35, n.6, p.2359-2367, 2006.

Data de recebimento: 06/07/2011

Data de aprovação: 10/01/2012 